\title{
EXAMINATION OF HAUSA TERMS AND CONCEPTS USED OVER THE ELECTRONIC MEDIA IN THE EASTERN HAUSA DIALECT AREA
}

\author{
USMAN AHMADU MOHAMMED \\ Nigerian Defence Academy - Kaduna
}

ABSTRACT. The study is set up to examine Hausa terms and concepts used over the Nigeria electronic media. Specifically the study analyses the use of Hausa in the eastern Hausa dialect area where we sample Kaduna and Kano States in Nigeria. Through various instruments of research, the study comes up with various performances of the Hausa Broadcasters in terms of IOVs, IOAs, IOCs, and IOIs. The study identifies that there are various degrees of variations among Hausa Broadcasters in the use of terms and concepts in the electronic media in the eastern Hausa dialect area. These variations are observed at different levels i.e. among Hausa Broadcasters in the same electronic media within the same dialect area and across electronic media. These variations occasion various degrees of performances among Hausa Broadcasters in terms of IOAs. The study further identifies various degrees of performances in terms of IOCs, which result in various degrees of performances in terms of IOIs. The performances of the Hausa Broadcasters result in confusions and "breakdown of communication" as reported by Hausa listeners. These variations and inconsistencies in the use of Hausa terms and concepts over the electronic media are tied up to various factors. The lack of a language monitoring body saddled with the responsibility of supervising Hausa language development in the media may be the cause of such discrepancies in the use of terms of concepts over the electronic media in the eastern Hausa dialect area.

\section{General Introduction}

Language Planning and Management (LPPM) have been the pre-occupation of Agencies/Agents and Scholars for decades. Since language is a social and dynamic phenomenon, the tasks that involve LPPM are constantly reviewed in order to meet up with current linguistic demands. The constant review of the LPPM is aimed at up-dating the language(s) with a view to interpret and express new ideas and innovations in various fields of human endeavours. This study aims at examining the use of Hausa terms and concepts in the Electronic Media in the Eastern Hausa Dialect Area. The electronic Media in their efforts to disseminate information, educate etc., do not only spread the language i.e. Hausa but also expand it with a view to coping with the modern day innovations in Sciences, Politics and Technology. 
Hausa is one of the major Nigerian languages, which has received significant attention from various Agencies/Boards, Agents and Scholars within and outside the Country i.e. Nigeria. The polito-administrative development of Nigeria, which occasioned the proliferation of Media establishments (mostly operating without a central language Committee or Board or Data Bank), has resulted in allegations of disorderly use of Hausa over the electronic Media.

Nigeria was a British colonial administrative structure, which was realized in 1914 by the amalgamation of the then two Protectorates - Northern and Southern into a single political entity. In 1946, three (3) Regions were created. Later in 1963, another Region was added and in 1967, the then four (4) Regions were divided into twelve (12) States. The number of States rose to nineteen (19) in 1976, to twenty-one (21) in 1987 and to thirty (30) in 1991. Few years later in 1996, six (6) States were created increasing the number of States to thirty-six (36). Out of these States, nineteen (19) including Abuja (The Federal Capital Territory) have Federal and/or State owned Radio and/or Television station(s), which broadcast News and/or feature programmes in Hausa.

Hausa is the language predominantly spoken by millions of people in Northern Nigeria and the other Countries in West African Sub-region neighbouring Country i.e. Niger Republic. Hausa speakers are also numerous in the Diaspora in Countries along the former Trans-Saharan Trade route and the Pilgrimage route. The Hausa were known to be essentially traders and religious adventurers who used to travel to Mecca for pilgrimage on foot. They settled on their way to and/or from Mecca in Countries like Cameroon, Chad, Sudan, and Libya etc. One interesting fact about the Hausa is the degree of Language Maintenance and Loyalty that made them (the Hausa) to retain not only their language but also their culture in the Diaspora where they formed communities in places referred to as Zango (temporary settlement) or Unguwar Hausawa (Hausa ward). These Hausa communities are also found in the Southern part of Nigeria, especially in urban centres in places called Sabon gari or simply Sabo which means "new settlement". The same appellation is found in Cameroon and Chad in a corrupted form sabangali or sabon gari for the Hausa settlements. In all these communities within or outside Nigeria, the language i.e. Hausa is used as "Communal or Home language". They (the Hausa) frequently keep up with the Hausa programmes in BBC (Hausa service), Radio Deutsche Welle (Germany), VOA (Voice of America) and Radio Nigeria Kaduna in Nigeria, which has relatively wider signal range. The multitude of electronic Media establishments that use Hausa for News and feature programmes, indicates the fact that Hausa is not only relied upon for personal communicative needs but also as means for acquiring information. These reasons necessitate the use of Hausa over the electronic Media in Nigeria and abroad. Those who depend on Hausa for communicative and educative purposes include Native Speakers as well as the Non-Native Speakers whose number is on the increase for the past decades. 
The Native and Non-Native Speakers of Hausa listen to Hausa News and feature programmes over the electronic Media.

Hausa belongs to the Semitic family of Afro Asiatic Phylum. Further classification indicates that the language belongs to the West Chadic. The family comprises several dialects. Ahmed and Daura (1970) identify seven (7) dialects of Hausa viz. a) Kananci, b) Sakkwatanci c) Katsinanci, d) Zazzaganci, e) Hadejiyanci, f) Dauranci and g) Bausanci (i.e. the Bauchi dialect) (cf. also Adamu (1970) and Abubakar (1983)). Various Agencies were created to serve as centres for the spread and standardisation of the language. Among these Agencies are: Gaskiya Corporation, which was established in 1945, the Northern Region Literature Agency (NORLA) in 1954, the Hausa Language Board (HLB) in 1955, the Northern Nigerian Publishing Company (NNPC) in 1966 and then the Centre for the Study of Nigerian Languages (CSNL) that began to publish the Journal Harsunan Nijeriya in 1970. The efforts of these Agencies at different times were geared towards the standardisation of Hausa orthography and lexis on one hand (cf Yahaya (1988)) and the spread of the language on the other. At different times, UNESCO and more recently the Centre Linguistique et historique par Tradition Oral (Centre for Linguistic and Historical Studies by Oral Tradition) in Niamey, under the auspices of the OAU had tried to harmonize Hausa orthographies across international boundaries. Nevertheless this effort failed due to vested interests of the Anglophone and Francophone States. There was no attempt by either these Agencies mentioned above or any of the organisations, to look into Hausa terms and concepts over the electronic Media within Nigeria where the creation of States resulted in the establishment of electronic Media houses, which operate without Language Committee or Board. This, in turn leads to uncoordinated or ad hoc selection of translated terms from the English version of the News.

In light of the significance of Hausa for socio-political development of Nigeria particularly in facilitating vertical and horizontal communications (Brann 1993), this study examines the problems emanating from the use of Hausa. Specifically the study looks at cases of "in-house and out-house" consistencies and/or inconsistencies in the use of Hausa terms and concepts. The examinations are expected to reflect the degree of convergence and divergence of the performances of the Hausa Broadcasters/Editors within and across electronic Media in the Eastern Hausa Dialect Area. In addition the study considers also the adequacies and inadequacies of the use Hausa terms and/or concepts among Hausa Broadcasters/Editors in the Area.

The uncoordinated efforts of the Hausa Broadcasters/Editors in the use of terms and/or concepts over the electronic Media in the Eastern Hausa Dialect Area may lead to what could be termed as "Parallel Enrichment" of the language, which consequently would confuse and or mis-inform Hausa Listeners. 


\subsection{Objectives}

The general aim of the study is to examine the nature and use of Hausa terms and concepts in the electronic Media in the Eastern Hausa Dialect Area in order to observe "in/out-house inconsistencies" and "linguistic mismanagement" resulting from ad hoc use of terms and concepts in order to cope with the trend and development in the society. Specifically, the study looks at:

- the use of terms and concepts in various electronic Media that broadcast News and feature programmes in Hausa in the Eastern Hausa Dialect Area.

- the level of adequacy in the use of terms and concepts among Hausa Broadcasters/Editors.

- the level of "in/out-house" consistencies and inconsistencies in the use of terms and concepts among the Hausa Broadcasters/Editors.

\section{Method and Procedures}

\subsection{Research Method}

This type of study various approaches may be employed depending on the focus of the study.

Linguists, Sociolinguists and Scholars interested in the use of language have designed various approaches, which are aimed at determining of the use language(s) in its social context. The consensus among these Scholars is that this type of Research may be handled in different ways depending on the aims and objectives of the Research. W.N. Francis in his book titled: Dialectology: An Introduction (1983) identifies four approaches viz:

a) the Traditional Approach which focuses on past events. Thus this type of approach is diachronic and item centred i.e. historical in nature,

b) the Structural Approach which is not historical in nature i.e. synchronic. This approach is essentially system centred. The structural approach has always been concerned with the forms,

c) the Generative Approach which is panchronic. This approach is rule centred. The Generativists use this approach. These Scholars hold the view that language is rule governed. According to them to learn a language is to internalise the rules that governed the use of that language,

d) the Sociolinguistic Approach is also panchronic but Speaker centred. The Sociolinguistic Approach is concerned with who speaks what, with whom, where and when? This type of analysis investigates language in the social context. Thus our Research falls within the scope of the Sociolinguistic Approach since we are concerned with the investigation of Hausa in the electronic Media. 
In as much as we are interested in determining the cases of variations in the use of Hausa terms and concepts within and across the Media establishments our standard is the Standard Hausa, which is mainly based on the Kano dialect. Hausa in the Media: A Lexical Guide by Mclntyre and Meyer-Bahlburg (1991) serves as the reference guide in the identification of the case or cases of variations in the use of terms and concepts. That means that the terms and/or concepts used in any Media establishment(s) are checked against the form(s) in the reference 'Guide. This is in order to determine case or cases of in-/out-house inconsistencies.

There are various Methods of Research. Among these Research Methods we have the Historical Method, which accounts for the past events, the Descriptive Method, which accounts for the existing situations, the Experimental Method, which is concerned with the evaluation of relationship between variables and the Analytical Method that concentrates on Statistics not only to describe but also to interpret the data. Ndagi (1984:99) argues that Descriptive Method

is concerned with the collection of data for the purpose of describing and interpreting conditions, practices, beliefs, attitudes etc. However the central method is not just the description of what is but (also) the discovery of meaning ...

The second Method adopted for the analysis in this study is the Analytical Survey Method, which is not only descriptive in nature but also interpretative in its statistical sense. Statistics, which is part of the Analytical Survey Method, is used in this study to determine various degrees of variation in the use of terms and concepts in electronic Media. The Analytical Survey Method presents an interesting description of the method, which is aimed at reducing data to figures for the sake of interpretations. There figures that represent different statistical observations are used to unravel certain realities. The analytical survey method comprises two components, each of which is determined by certain statistical activities aimed at the classification and organisation of the data. The components of the Analytical Survey Method are: a) Descriptive Statistics and b) Inferal Statistics. For the sake of this study we consider Descriptive Statistics, which comprises statistical observations such as: Mean, Standard Deviation, Average Deviation and Dispersion Range. These statistical observations are measurements that are classified under the Central Tendency. Two scales are used in this study to determine the two instances in the use of terms and concepts. These instances are: a) the inconsistencies in the use of terms and concepts where we distinguish between the degree of inconsistencies within each Media establishment i.e. in-house inconsistencies and b) the degree of inconsistencies across Media establishments i.e. out-house inconsistencies. For these types of considerations the statistical units of measurements we use are: a) the 
instances of inconsistencies among the respondents within or across the Media establishments are measured with the statistical unit referred to as the "Instance of Inconsistency" (henceforth IOI) while b) the adequacies of the renditions of terms and concepts from the SL to the TL is measured with the statistical unit referred to as the "Instance of Adequacy" (henceforth $I O A$ ) and the instances of variations among the Respondents within or across the Media establishments are measured with the statistical unit referred to as the "Instance of Variation" (henceforth IOV).

In order to reinforce the Descriptive Method we thought necessary and reasonable to adopt what Milroy (1987:3) refers to as the "Introspective Method" which according to him provides "accessibility to linguistic structures and organisations." The Introspective Method allows the Researcher to use his competence in order to determine certain situation i.e. to identify, describe, and interpret linguistic phenomena. Leedy (1974:30) argues that the Descriptive Method is the "intense looks with accuracy at a phenomenon of the moment and describe what precisely what one has seen".

\subsection{Sampling}

Sampling procedures in this study takes into account some selected variables such as the dialectal differences, the educational attainment, and the experience of the Hausa Broadcasters/Editors. Sampling procedures determine the universe of the research and its populace. The criteria used in the selection of this representative sample are related to whether the area of broadcast is originally Hausa speaking area i.e. endoglotic or the area is not originally Hausa speaking area i.e. exoglotic. Within the endoglotic area we consider Kaduna, Kano States representing the Eastern Hausa dialects. In the analysis we consider Hausa Broadcasters in the Electronic Media is these States. In sum we have eight (8) Media establishments. Hausa Editors/Broadcasters in these electronic Media are administered the Questionnaire designated to them. Five to Ten Questionnaires are sent to each Media establishment. This is because the number of Hausa Broadcasters/Editors in these Media Houses varies from five to ten. A total number of hundred (100) Questionnaires are sent to these Electronic Media for the Respondents who are Hausa Broadcasters/Editors.

The theoretical basis of sampling adopted for the selection of Hausa Listeners is from Labov's (1972b:37) concept of "random sampling." This theoretical concept advocated by Labov (op. cit.) is meant to select Respondents through a process where each individual within the area of the study is given a chance of being considered as a Respondent. A technique that is said to involve randomisation, various procedures are adopted. Among these procedures include: a) Roulette Wheel, b) Lottery Method, c) Table of random numbers etc. 
These procedures of random sampling are aimed at arriving at an un-bias sample. The central idea underlining this concept is to extract from the target population i.e. the entire population under study, a Research population i.e. a Research sample devoid of bias. The number of hundred (100) Respondents is selected through this process in each State sampled out here for the purpose of this study. Two hundred (200) Respondents/Hausa Listeners are sampled out of two States. These Respondents are administered the appropriate Questionnaires for the Hausa Listeners/Viewers. The sampling procedure does not take into account social variables such as sex, educational background, and age.

\subsection{Statistics}

Statistics is yet another instrument used in this study. Statistics is a scientific means of taking numerical facts and translating them meaningfully. In this study Statistics is used as an instrument of interpretation while the Questionnaires are used for the exploration of the field of the study, Statistics helps in the interpretation of the product obtained from the field of study. Statistics is used to determine with accuracy the levels adequacies, consistencies and inconsistencies among the electronic Media in the uses of terms and concepts. In order to measure statistically the degree of adequacies among the electronic Media, the unit of the measurement used is the "Instance of Variation" (henceforth $\mathrm{IOV}$ ), which is the score as result of inadequate use of a term and/or concept. While the unit for the measurement of the consistencies is the "Instance of Inconsistency" (henceforth IOI) which is the score as result of inconsistent use of a term and/or concept. Statistics has its own characteristics in terms of organisation and classification of the data obtained. Since in the Research we use it (i.e. Statistics) as an instrument for the interpretation of the data obtained, it is deemed necessary to discuss these characteristics in order to understand the operational system of the instrument. The characteristics of the instrument i.e. Statistics are:

a) Central Tendency,

b) Data Spread,

c) Relationship,

d) Correspondence with Nature, in this study we consider only two characteristics namely the Central Tendency and the Data Spread. This is due to the fact that in this study we are concerned with Descriptive Statistics. The Central Tendency is the central point of numerical facts where two or more scores are put together with the view to obtaining the average. The Central Tendency is used in this study in order to determine how the scores (which are the total number of either $I O V_{s}$ or $I O I s$ ) of the Respondents converge or diverge within or without the electronic Media selected here for the sake of this study. This is to reflect the degree of consisten- 
cies or adequacies of the electronic Media in uses of terms and concepts. The Mean is the precise centre of the amalgamated scores.

The Data Spread comprises some characteristics that are aimed at reflecting the disparity. The Data Spread is yet another method through which one can determine the range of disparity. Here in this study the range of the disparities of various Respondents and electronic Media can be determined through the use of the Data Spread which has three composites viz: a) the Dispersion Range (DR), b) the Average Deviation (AD) and c) the Standard Deviation.

\subsection{Theoretical Framework}

The Theoretical Framework adopted in this study is adapted from Simpson's (1985) "Translation Criticism" theory with some modifications due to the focus of our research, which is the case of the study of inconsistencies in the use of terms and concepts over the Media. Simpson's theory is based on "positive and negative points" of the translation in the electronic Media. This study is particularly concerned with the negative points since one of the objectives of this study is to determine the level of inconsistencies within each electronic Media and across the electronic Media which use Hausa for the broadcast of News and feature programmes. Moreover we intend to use the principle of Adequacy as reflected in Vinay and Darbelnet (1958) in order to assess the level of adequacy of the terms and concepts used i.e. to determine whether the equivalence is well motivated. For instance when there is a case of multiple interpretations of a concept we use our standard obtained from the "Hausa Lexical Guide" to determine the most adequate interpretation in which the sub-categorisation frame is captured.

\section{Analyses}

The analyses are centred on the Respondents' performances in terms of IOVS and IOAs within individual electronic Media in each State sampled here for the sake of this study. In addition the analyses are concerned with various degrees of IOIs among the electronic Media within the dialect Area. These analyses are correlated with the characteristics of Hausa Listeners. In addition, the analyses are expected to reflect the extent to which these individual electronic Media converge and/or diverge in the application of terms and/or concepts over the electronic Media.

In Kaduna State there are five electronic Media: 1) the Nigerian Television Authority (NTA-Kaduna), which is Federal owned, 2) the Federal Radio Corporation of Nigeria (FRCN Kaduna) also Federal owned, 3) the Kaduna State Me- 
dia Corporation (KSMC) a State owned, 4) the Kaduna State Television (KSTV) State owned and 5) the Desmims Independent Television (DITV) a Private owned.

In NTA-Kaduna there are four Respondents. There is a cross dialectal usage in the Media. For instance all the Respondents use the Eastern varieties of Hausa but in addition, the Respondents A and B use Katsinanci and Sakkwatanci respectively, which are Western varieties of Hausa. In spite of the fact that $\mathrm{A}$ and $\mathrm{C}$ are from Kano State $\mathrm{A}$ uses Katsinanci in addition to Kananci. This may be the influence of Katsina when it was part of Kaduna State. None of the Respondents has formal training in Hausa Translation in spite of the fact that they are all Native Speakers of Hausa. This might have contributed to the low performances and uncoordinated efforts of the Respondents in the use of terms and concepts (as demonstrated by the statistical evidences below). The training is expected to provide them with techniques of utilising the linguistic resources at their disposal as Native Speakers of the language i.e. Hausa. All the Respondents have concluded Diploma level in subjects related to Mass Communication and Journalism. These fields of Studies provide the recipients different techniques from Linguistic Management. There is an assumption, which may be deduced from the Theories on Mass Communication thus far. The assumption is that language issues are taken for granted as no section is provided on the Theories. We can observe that the Respondents possess good skills in the two working languages i.e. English, Hausa, and an average years of experience of 10.75 years. Nevertheless, these qualifications though they are significant they need to be added up to constant exposure to the techniques of Linguistic Management and Language Development. This is with the view to curtail cases of variations and inadequacies in the use of terms and concepts over the electronic Media as reflected in the performances of the Respondents.

The Mean of the Hausa Broadcasters/Editors in terms of $10 \mathrm{Vs}$ in NTAKaduna is 72.75 that reflect various performances. We can observe from the individual deviations that two Respondents: $\mathrm{A}$ and $\mathrm{D}$ deviate above the central point by 8.25 and 21.25 respectively while 2 Respondents: B and C deviate bellow the central point by 1.75 and 27.75 respectively. When we consider the deviations generally we observe that the Standard Deviation of the Respondents is 7.37 while the Average Deviation is 14.75 . The highest performance in terms of $I O V s$ is reflected against the Respondent $\mathrm{D}$ who has the highest score above the central point while the lowest performance is reflected against the Respondent $\mathrm{C}$ who has the highest deviation below the central point. The Dispersion Range in terms of $10 V_{S}$ is 49 . The Dispersion Range reflects the difference in performances between the highest scorer and lowest scorer of the group. The performances of the Respondents in this Media present different realities in terms of IOAs. The Mean of the Respondents in this Media in terms of IOAs is 72.25 thus two Respondents: $B$ and $C$ who possess deviations below the central 
point in terms of IOVs present deviations above the central point in terms of IOAs while those Respondents: A and D who possess deviations above the central point in terms of IOVS present deviations below the central point in terms of $I O A s$. When we consider the individual deviations of the Respondents in terms of IOAs can observe that the Respondent $\mathrm{B}$ and $\mathrm{C}$ present deviations above the central point while the Respondents $\mathrm{A}$ and $\mathrm{D}$ present deviations below the central point. Those Respondents who present high deviations below the central point reflect low levels of Instances of Adequacy (IOAs). The Standard Deviation of the Respondents in terms of IOAs is 7.37 while the Average Deviation is 14.75. These statistical measurements reflect various performances of the Respondents in terms of IOVS and IOAs. When we consider the Instances of Consistencies (IOCs) and the Instances of Inconsistencies (IOIs) of the Respondents we can further observe that the Respondents reflect $4.31 \%$ in terms of IOCs. The Respondents present $95.69 \%$ of IOIs. This reflects the fact that the Respondents do not only present variations in the use of terms and concepts but also they inconsistently use inadequate terms and concepts. We can further observe that performances of the Respondents reflect greater percentage of IOIs as compared to their performances in terms of IOCs. When we consider the total performances of the Respondents in terms of both $1 O \mathrm{Vs}$ and $1 \mathrm{OAs}$ we can observe that the Respondents reflect $50.17 \%$ in terms of $I O V s$ and in terms of $I O A s$ the Respondents reflect $49.82 \%$. This shows that the performances of the Respondents in terms of IOVs are greater than their performances in terms of IOAs.

In the FRCN-Kaduna there are six Respondents. There is a mixed dialectal use in the Electronic Media. The Respondents use the following dialects: Kananci, Sakkwatanci and Zazzaganci. The cross-dialectal use may be a source of variations among the Respondents because no Speakers of any two dialects of the same language have a congruent interpretation of an event(s). Out of all the Respondents in this Media establishment only the Respondent $\mathrm{C}$ who is a Fulani while all others are Native speakers of Hausa. Here unlike the previous electronic i.e. the NTA-Kaduna there is a somehow a mixed ethnic composition in FRCN-Kaduna. Nevertheless, the Respondents in FRCN-Kaduna have concluded some level of education in Hausa. Here in this electronic Media none of the Respondents has undertaken courses related to Mass Communication or Linguistics. In addition to the educational background of the Respondents in this Media establishment, the Respondents present a relatively higher average duration of experience. The average duration of the Respondents is 15.66 years. Only the Respondent B has working experience elsewhere apart from FRCNKaduna. In spite of the fact that the Respondents have a good competence in the skills of the two working languages, they equally present variations and inadequacies in the use of terms in concepts.

The Mean of the Respondents in terms of IOVs is 70.33. From the Mean we can observe various individual deviations of the Respondents in this elec- 
tronic Media. The Standard Deviation of the Respondents in terms of IOVs is 31.29 while the Average Deviation is 12.77 . From these deviations we can observe that four (4) Respondents i.e. B, C, D, and F present different degrees of performances below the central point in terms of IOVs while two Respondents: $\mathrm{A}$ and $\mathrm{E}$ perform above the central point. In NTA-Kaduna we have only two Respondents who perform below the central point in term of IOVs. The highest performance in terms of IOVs is reflected against the Respondent $\mathrm{E}$ with an individual deviation of 37.67 above the central point while the lowest is reflected against the Respondent $\mathrm{C}$ with an individual deviation of 25.33 below the central point in terms of IOVs. Thus the Dispersion Rage of the Respondents in terms of IOVs is 63. Only two Respondents: A and E present deviations below the central point in terms of IOAs. The Mean of the Respondents in terms of $I O A s$ is 74.66. From the Mean of the Respondents in terms of IOAs we can observe various individual deviations. The Standard Deviation is 31.30 while the Average Deviation is 12.78. These individual deviations reflect the fact that four (4) Respondents: B, C, D, and F present performances above the central point in terms of IOAs while only two Respondents: $\mathrm{A}$ and $\mathrm{F}$ present some degrees of performances below the central point in terms of IOVs. Only fifty per cent $(50 \%)$ of the Respondents in NTA-Kaduna present performances above the central point in terms of IOAs while sixty seven per cent (67\%) perform above the central point in terms of IOAs in FRCN-Kaduna. When we consider the performances of the Respondents in terms of both the IOVS and the IOAs, we can observe that the Respondents reflect $48.50 \%$ in terms of $1 \mathrm{OVs}$ and in terms of IOAs the Respondents reflect $51.49 \%$. This shows that the Respondents reflect higher performances in terms of IOAs than their performances in terms of IOVs. The percentage of performances of the Respondents in FRCN-Kaduna in terms of IOAs is greater than the percentage of the Respondents in NTAKaduna. In terms of IOCs the scores of the Respondents represents $1.72 \%$ while their scores in terms IOIs represents $98.28 \%$. This shows that the performances of the Respondents in terms of IOIs greater than their performance in terms of IOCs. When we consider the levels of inconsistencies and consistencies in the NTA-Kaduna and FRCN-Kaduna we discover that FRCN-Kaduna is $1.72 \%$ consistent while the NTA-Kaduna is $4.31 \%$ consistent. Thus the NTA-Kaduna is more consistent than the FRCN-Kaduna. When we consider the levels of the adequacy of the FRCN-Kaduna which is sixty seven per cent $(67 \%)$ above the central point in terms of IOAs while the NTA-Kaduna fifty per cent $(50 \%)$ it means that the FRCN-Kaduna is more in terms of individual performance in IOAs. This reflects the fact that the performances of the Respondents may be inadequately consistent. This may be the reason why the FRCN-Kaduna has high percentage in terms of IOAs but low percentage in terms of IOCs in comparison with NTA-Kaduna, which has high percentage in terms of IOCs and low percentage in terms of IOAs. 
There are six Respondents in the KSMC. The average duration of the Respondents in KSMC-Kaduna is 12.66 years. We can observe that these Respondents possess a longer average of experience than the previous Media establishments i.e. the NTA-Kaduna and the FRCN-Kaduna. The Respondents A, C, $\mathrm{D}, \mathrm{E}$ and $\mathrm{F}$ do not have any formal training in Translation except the Respondent $\mathrm{B}$. We expect that the Respondent $\mathrm{B}$ is going to have an additional advantage over others who do not have any formal training because he might have acquired techniques in the Linguistic Management. As for dialectal usage of the Respondents in KSMC-Kaduna, the Respondents: A, B, D and E use the Eastern varieties of the language i.e. Kananci while the Respondent $\mathrm{F}$ uses all the dialects "as appropriate." The tendency of free dialectal choice in Linguistic Management in the electronic Media may be a source of variations among the Respondents. Another source of possible variations among the Respondents is the fact that some Respondents possess educational backgrounds un-related to their profession as Hausa Broadcasters. This is the case of the Respondents B, E and F. Though most of the Respondents in this establishment are Hausa Native Speakers and sufficiently experienced, it is not enough to guarantee adequate use of the language i.e. Hausa for the purposes of Broadcasting.

The Mean of the performances of the Respondents in terms of IOVs is 60.16. The Standard Deviation of the Respondents is 32.38 while the Average Deviation is 13.22. An observation on these deviations reveals that four (4) Respondents: A, B, C and D reflect deviations below the central point while the Respondents $\mathrm{E}$ and $\mathrm{F}$ perform above the central point. The Respondents who perform above the central point in terms of IOVs reflect performances below the central point in terms of IOAs. The Respondents $\mathrm{E}$ and $\mathrm{F}$ present deviations below the central point. The highest performance in terms of $I O \mathrm{Vs}$ is reflected against the Respondent $F$ while the lowest performance is reflected against the Respondent D. This results to the Dispersion Range of 55, which is higher than that of the NTA-Kaduna and lower than the FRCN-Kaduna. The Mean of the Respondents in terms of IOAs is 84.83. The individual deviations of the Respondents in terms of IOAs reflect the fact that four (4) Respondents: A, B, C and D perform above the central point in terms of IOAs while the Respondents $\mathrm{E}$ and $\mathrm{F}$ perform below the central point. The Standard Deviation of the Respondents in terms of IOAs is 32.39 while the Average Deviation is 13.22. The IOCs of the Respondents in Media establishment represents $3.56 \%$ while the IOIs represents $96.66 \%$. This shows that the performances of the Respondents in terms of IOIs are greater than their performances in terms of IOCs. We can observe that the IOCs of the Respondents in KSMC-Kaduna are greater than those of FRCN-Kaduna while smaller than those of NTA-Kaduna. Considering the performances of the Respondents in both the IOVs and IOAs of the Respondents in KSMC-Kaduna we can observe that in terms of IOVS the performances of the Respondents represent $41.49 \%$ while in terms of IOAs the performances 
of the Respondents represents $58.50 \%$. The performances of the Respondents in terms of IOAs are greater than their performances in terms of IOVs. However, in terms of the individual performance in IOAs the KSMC-Kaduna is same with that of the FRCN-Kaduna with $67 \%$. However, both the FRCN-Kaduna and the KSMC-Kaduna present lower percentage in comparison with NTA-Kaduna in terms of $I O C s$. This reflects the case of consistent inadequacy.

There are five Respondents in KSTV-Kaduna. The Respondents have good competence in the skills of the two languages i.e. Hausa and English. This is in addition to the fact that most of them had formal training and they are Native Speakers of Hausa. In spite of these linguistic assets and qualification there is high tendency of variations and cases of inadequacies among the Respondents, which is partly due to the fact that most of them have educational backgrounds un-related to Linguistic Management and Language Development as observe with the Respondents in the previous Media establishments. The Respondents possess a high average duration of working experience. Nevertheless we can observe that the Respondents in all the electronic Media considered this far are free to use any dialect. This practice needs technical expertise. This is with a view to gain wider range of intelligibility and avoid confusion.

The Mean of the Respondents in this establishment is 76.4 in terms of IOVs. The individual deviations reflect the fact that four (4) Respondents: A, B, $\mathrm{C}$ and $\mathrm{E}$ perform below the central point in terms of IOVS while the Respondents $\mathrm{D}$ performs above the central point. The Standard Deviation is 23.79 and the Average Deviation is 10.64. The highest performance in terms of IOVs is reflected against the Respondent D while the lowest performance is reflected against the Respondent E. The Dispersion Range is 47. The Mean of the Respondents in terms of IOAs is 68.6. Thus the individual deviations of the Respondents in terms of IOAs reflect the fact that the highest performance is reflected against the Respondent $\mathrm{E}$ while the lowest performance is reflected against the Respondent $\mathrm{D}$. We can deduce that the Respondents who present performances below the central point in terms of $1 \mathrm{OVS}$ are those who reflect performances above the central point in terms of IOAs. The Standard Deviation in terms of IOAs is 23.79 while the Average deviation is 10.34 . The highest performance in terms of $I O A s$ is reflected against the Respondent $\mathrm{E}$ while the lowest is reflected against the Respondent $\mathrm{D}$. The Dispersion Range of the Respondents in terms of 47 . The IOCs of the Respondents $2.62 \%$ while the IOIs represents $97.36 \%$. We can observe that the percentage of IOIs of the Respondents is greater than the percentage of the Respondents in terms of IOVs. It can be observed that $80 \%$ of the Respondents perform above the central point in term of IOAs which is a performance above all the previous Media establishments but in terms of IOCs the score the $2.62 \%$ which is higher than the FRCNKaduna and lower than the NTA-Kaduna and KSMC-Kaduna. The percentage of performances of the Respondents in terms of $1 O I_{s}$ is $97.36 \%$. Thus it can be 
observed that the performance of the Respondents in terms of IOIs is greater than their performance in terms of IOCs.

All along in this State we have been dealing with either State or Federal owned Media. The DITV is private owned Media, the only one in the North for now. There are two Respondents in the electronic Media. It can be observed at the onset that there are fewer Respondents compared with the previous Media establishments. This may be for economic reasons. The average years of experience of the Respondents are 5 years. The average years of experience of the Respondents in this Media is smaller than the previous Media. The Respondents are Native Speakers of Hausa from Katsina. We are expecting the Respondents to use Katsinanci but the Respondents use Kananci instead. The Respondents claim to possess a Very good competence in the two functional languages i.e. Hausa and English but they never had formal training in translation thus it is very difficult for the Respondents to manage efficiently the linguistic assets at their disposal. In addition it is observed that the Respondents did not acquire educational background related to Linguistic Management and/or Broadcasting. Generally it is believed that any educational background fits the broadcasting profession. This assumption allows many Broadcasters with varied educational backgrounds un-related to Broadcasting. This among others contributes to the lack of proper linguistic management.

The Mean of the Respondents in this Media establishment in terms of IOVs is 106 with individual deviations that reflect the fact that the Respondent B performs above the central point while the Respondent A performs below the central point. The Standard Deviation is 22.62 while the Average Deviation or the Respondents in terms of IOVs is 16 . The highest performance in terms of $I O V s$ is reflected against the $\mathrm{B}$ and the lowest performance is reflected against the Respondent A. The Dispersion Range of the Respondents in terms of IOVS is 32. The Respondent A who performs below the central point in terms of IOVs presents a higher performance in terms of IOAs. The Respondent B who performs above the central point in terms of $1 \mathrm{OVS}$ presents a lower performance in terms of IOAs. The Mean of the Respondents in terms of IOAs is 39. The individual deviations of the Respondents in terms of $1 O A s$ show that the highest performance in terms of IOAs is reflected against the Respondent A while the lowest performance is reflected against the Respondent B. The Standard Deviation of the Respondents is 22.62 while the Average Deviation is 16. The Dispersion Range of the Respondents is 32 . The IOCs of the Respondents is 35 while the $1 O \mathrm{Ol}$ is 255 . It is interesting to note that in terms of the performance of the Respondents above the central point we have $50 \%$ which can be equated with the performance of the NTA-Kaduna but lower than the performances of the FRCN-Kaduna, KSMC-Kaduna and KSTV-Kaduna. On the other hand in terms of IOCs the DITV possesses $12.06 \%$ a performance greater than all the previous Media establishments in the State. In terms of IOIs the Respondents possess 
87.94\%. This reflects the fact that the performance of the Respondents in terms of IOIs is greater than their performance in terms of IOCs. When we consider the total scores of the Respondents both in terms of IOVs and IOAs we can observe that the Respondents perform $73.43 \%$ in terms of $1 O \mathrm{VS}$ and in terms of IOAs the Respondents perform $26.89 \%$ in terms of IOAs. This shows the performance of the Respondents in terms of IOVS is greater than their performance in terms of IOAs.

Thus far we have considered five electronic Media in Kaduna State, which is one of the two States sampled to represent the Eastern dialect area. Twenty three (23) Respondents are Hausa Broadcasters/Editors. The frequencies of the Hausa Listeners/Viewers sampled in the State are as it follows: 40\% Always, 44\% Frequently, and $16 \%$ Sometime. From the foregoing we can observe that most Listeners/Viewers have made Hausa programmes as part of their life. Ninety four $(94 \%)$ of the Respondents prefer TV and Radio while six per cent $(6 \%)$ prefer Radio for Hausa programmes to the Radio only. Hundred per cent (100\%) listen to FRCNKaduna, fifty six per cent (56\%) listen to KSMC-Kaduna, Fourteen per cent (14\%) listen to Kano State Radio, Four (4\%) listen to Katsina state Radio, two per cent $(2 \%)$ listen to Zamfara State Radio, two per cent (2\%) listen to Rima Radio, four per cent (4\%) listen to the Voice of Nigeria Abuja. It can be observed that the Respondents in the State listen to Hausa programmes in both local Radio stations as well as electronic Media in the neighbouring States including States that are within the Western dialect area: Katsina, Zamfara and Sokoto States. Hundred per cent $(100 \%)$ listen to BBC-Hausa service, Ninety six per cent $(96 \%)$ listen to the Voice of America-Hausa service, eighty two per cent $(82 \%)$ listen to Radio Deutsche Welle-Hausa service, six per cent (6\%) listen to Radio Peking, four per cent $(4 \%)$ listen to Radio Teheran. It can be observed that the Respondents do not depend on local electronic Media for Hausa programmes but they equally depend heavily on Oversee electronic Media such as the BBC-London, VOA, Voice of Germany etc. A part from the Radio, the Respondents watch Hausa programmes over Television Stations. Eighty eight $(\mathbf{8 8} \%)$ watch Hausa programmes over the NTA-Kaduna, fourteen per cent $(14 \%)$ watch Hausa programmes over the KSTV-Kaduna, Six per cent $(6 \%)$ watch Hausa programmes over NTA-Katsina, two per cent $(2 \%)$ watch programmes over NTA-Abuja, four per cent $(4 \%)$ watch Hausa programmes over NTA-Sokoto, four per cent watch Hausa programmes over CTV-Kano, ten per cent $(10 \%)$ watch Hausa programmes over DITV-Kaduna. From the foregoing we can observe that the Respondents do not only listen to Hausa programmes over the international electronic Media and neighbouring States but Television Stations in the neighbouring States. It is interesting to note that the majority of Listeners/Viewers of Hausa programmes are males: $98 \%$ while only $2 \%$ are females. This may bring about the question of how to reach female Speakers of Hausa with new Hausa terms and concepts, which are constantly developed in order to interpret new events in the fields of Sciences, Technology etc. 
The ethnic composition of the Respondents is as it follows: Hausa $32 \%$, Fulani $12 \%$, Kanuri $10 \%$, Babur/Bura 4\%, Nupe $12 \%$, Nbagi $10 \%$, Ngamo 4\%, Higi 4\%, Shuwa Arab 4\% and Kaje 8\%. It can be observed that the ethnic composition of the Respondents is mixed. This means that those who depend on Hausa programmes over the electronic Media are not only Hausa Native Speakers of Hausa but also Hausaphile and Hausaphone who belong to various tribes in Northern Nigeria. Some Respondents have acquired Hausa in non-Hausa speaking area such as Adamawa State $8 \%$, Yobe 4\%, Borno 2\% but some others have acquired Hausa in the two Hausa speaking areas: a) Western: Katsina $12 \%$ and Zamfara $8 \%$ and b) Eastern: Kano $10 \%$ and Kaduna $56 \%$. It is interesting to note that Hausa is acquired not only in Hausa speaking areas but also nonHausa speaking areas. This phenomenon raises the issue of varieties of Hausa not only along dialectal lines but also varieties of Hausa along socio-ethnic and linguistic lines. It is important to take these issues seriously in the development of the language i.e. Hausa. Questions such as who (ethnicity) speaker of which language(s) (linguistic background) acquired Hausa where may be vital in Language Development. These types of questions are very important because the un-coordinated efforts in the development of Hausa may end up as "noises." In order to support this claim we discover that $82 \%$ of the Respondents reported that they do not understand some Hausa terms and concepts in Hausa programmes over the electronic Media.

In Kano State there three electronic Media: two of the electronic Media are State owned Media and the other is a Federal owned Media. The Respondents possess an average years of experience of 9.5 years. Though all the Respondents are Hausa Native Speakers of Hausa and in addition they possess a very good competence in the two working languages i.e. Hausa and English, most of them do not have any training in Translation as their counterpart in the previous electronic Media. There is a general assumption that when an individual is endowed with linguistic resource he may be able to manage it for communicative purposes in the Mass Communication. The absence of formal training as observed in the Media is a serious set back to the profession and the language of broadcast, which may lack proper approach in its developmental processes. This is due to the fact that the broadcaster (s) lacks the technical knowledge in Linguistic Management for efficient utilisation of the linguistic resources available to them.

In Kano State Radio (KSR-Kano) the situation as regard the use of the language of broadcast i.e. Hausa is also characterised with variations in the use of terms and concepts. These variations in the use of terms and concepts over the electronic Media differ from one individual Hausa Broadcaster to another. The Mean of the Respondents in term of IOVs is 67.16. The individual deviations of the Respondents in this electronic Media reflect the fact that three Respondents: $\mathrm{C}, \mathrm{D}$ and $\mathrm{F}$ perform below the central point while the three others perform 
above the central point. The Standard Deviation of the Respondents in terms of $I O V S$ is 15.9 while the Average Deviation is 6.49. The highest performance in terms of IOVs is reflected against the Respondent $\mathrm{E}$ while the lowest performance in terms of IOVS is reflected against the Respondent $\mathrm{C}$. Thus the Dispersion Range of the Respondents is 18. In terms of IOAs the Mean of the Respondents is 77.83. The individual deviations of the Respondents in terms of IOAs show that three Respondents: A, B and E reflect performances below the central point in terms of IOAs. The three other Respondents $\mathrm{C}, \mathrm{D}$ and $\mathrm{F}$ reflect performances above the central point in terms of IOAs. The Standard Deviation of the Respondents in terms of IOAs is 15.92 while the Average Deviation is 6.5. The highest performance in terms of $1 O A s$ is reflected against the Respondent D while the lowest performance is performance is reflected against the Respondent $\mathrm{E}$. The Dispersion Range of the Respondents in terms of IOAs is 18. When we consider the scores of the Respondents both in terms of IOVS and IOAs we observe that the performances of the Respondents in terms of $1 O \mathrm{Vs}$ represent $46.32 \%$ while their performances in terms of IOAs is $53.67 \%$. This means that the Respondents possess better performances in terms of IOAs than their performances in terms of IOVs. The IOCs of the Respondents represents $4.71 \%$ while the IOIs represents $95.29 \%$. This shows that the performances of the Respondents in terms of IOIs are higher than their performances in terms of $1 O \mathrm{Cs}$.

We have observed various performances of the Respondents in this electronic Media both in terms of IOVS and IOAs. These performances reflect various individual deviations from the central points. These individual deviations represent the scores of the Respondents in both the Instances of variations and adequacies in the use of terms and concepts. Fifty per cent $(50 \%)$ of the Respondents score above the central point in terms of IOAs. The IOCs of the Respondents is $4.71 \%$ while their performance in terms of $I O I s$ is $95.29 \%$. This shows that the performance of the Respondents in terms of IOIs is greater than their performance in terms of IOCs.

The CTV-Kano is yet another State owned Media. The five Respondents of the electronic Media who are Hausa Native Speakers of Hausa possess a high linguistic profile. Nevertheless, as observed in the previous Media establishments a high linguistic profile without formal training is not profitable in the broadcasting industry. This is due to the fact that the management of linguistic resources needs some technicalities that are acquired only through formal training. In addition to the lack of formal training which is endemic to the Media industry, Broadcasters often do not possess educational backgrounds that are related to broadcasting. These and other problems may be the sources of variations in the use of terms and concepts in the electronic Media.

The Mean of the Respondents in terms of IOVs is 76.8. The individual deviations show that three Respondents: $\mathrm{A}, \mathrm{B}$, and $\mathrm{D}$ perform below the central point. The Respondents $\mathrm{C}$ and $\mathrm{E}$ perform above the central point. The Standard Deviation of the Respondents in terms of IOVs is 19.14 while the Average de- 
viation is 8.56 . From the individual deviations we can observe that the highest score in terms of $I O V_{S}$ is reflected against the Respondent $\mathrm{E}$ while the lowest score is reflected against the Respondent $\mathrm{B}$. Thus the Dispersion Range of the Respondents in terms of IOVS is 30. In terms of the IOAs the Mean of the Respondents is 68.2. The Standard Deviation is 19.14 while the Average Deviation is 8.56. From these individual deviations in terms of IOAs we can observe that the highest performance in terms of IOAs is reflected against the Respondent $\mathrm{B}$ while the lowest performance is reflected against the Respondent $\mathrm{E}$. Thus the Dispersion Range is 30 . It can be observed that the Respondents $\mathrm{C}$ and $\mathrm{E}$ perform below the central point. This means that those Respondents reflect high instances of inadequacies compared with the other Respondents whose performances in terms of $I O A s$ also vary from individual to another. The total performances of the Respondents in terms of IOVs represents $52.96 \%$ while the total performances of the Respondents in terms of $I O A s$ represents $47.03 \%$. This shows that the percentage of the performances of the Respondents in terms of $I O V_{S}$ is higher than that of the performances in terms of IOAs. The IOCs of the Respondents is 41 which represent $5.65 \%$ of the total entry while the IOIs is 684 , which constitutes $94.35 \%$. This reflects the fact that the performance of the Respondents in terms of $I O I s$ is higher than their performances in terms of IOAs.

Considering the IOVs and IOAs of the Respondents in both CTV-Kano and KSR-Kano we can deduce that in each electronic Media there are three Respondents who perform below the central point in terms of IOVS while in terms of $I O A s$ there also three in each. However, the highest performance in terms of $I O V S$ is reflected against the Respondent E of the CTV-Kano but in terms of $I O A s$ the highest performance is reflected against the Respondent $\mathrm{F}$ in KSRKano. The CTV-Kano reflects $52.96 \%$ scores in terms of $I O V_{S}$ while the KSRKano reflects $46.32 \%$ in terms of IOVs. This shows that the CTV-Kano has the highest performance in terms of IOVs. The KSR-Kano reflects $53.67 \%$ in terms of IOAs while the CTV-Kano reflects $47.03 \%$ in terms of IOAs. This shows that the KSR-Kano has the highest performance in terms of IOAs. In terms of IOCs we can observe that the CTV-Kano scores $5.65 \%$, which is higher than KSRKano with $4.71 \%$ of $1 O C s$ while the performance of the Respondents in terms of IOIs $95.29 \%$. In both electronic Media there are $60 \%$ of the Respondents who perform above the central point ion terms of IOAs. The performance of the Respondents in terms of IOIs is higher than their performance in terms of IOCs.

The two previous electronic Media we considered above are State owned Media. The third Media in the State is a Federal owned. The NTA-Kano has six Respondents who are good in the two languages i.e. English and Hausa. All Respondents in NTA-Kano happen to be Hausa Native Speakers of Hausa as the other two Media in the State. The Respondents possess educational backgrounds related to either Hausa language or Mass Communication fields. Nev- 
ertheless, as observed in the other electronic Media the linguistic resources and Mass Communication techniques are not enough to prevent variations or inadequacies in the use of terms and concepts.

The Mean of the Respondents in NTA-Kano in terms of IOVs is 69.66. The Standard Deviation is 33.19 while the Average Deviation is 13:55. From the forgoing individual deviations in terms of IOVs we can observe that two Respondents: $\mathrm{B}$ and $\mathrm{D}$ perform above the central point and four Respondents: $\mathrm{A}, \mathrm{C}, \mathrm{E}$ and $\mathrm{F}$ perform below the central point. The highest performance in terms of IOVs is reflected against the Respondent $\mathrm{D}$ while the lowest performance is reflected against the Respondent 61. Thus the Dispersion Range of the Respondents in terms of IOVs is 63. The Mean of the Respondents in terms of IOAs is 75.33. The Standard Deviation is 33.2 while the Average Deviation is 13.55. From the individual deviations we can deduce that two Respondents: $B$ and $\mathrm{D}$ perform below the central point while four Respondents: A, C, E and F perform above the central point. The highest performance in terms of IOAs is reflected against the Respondent $F$ while the lowest performance is reflected against the Respondent $\mathrm{D}$. Thus the Dispersion Range of the Respondents in terms of IOAs is 63. When we consider total scores of the Respondents both in terms of IOVS and IOAs we can observe that the Respondents perform $48.04 \%$ in terms of IOVS and $51.95 \%$ in terms of $I O A s$. This means that the Respondents reflect higher percentage of $1 O \mathrm{As}$ than their percentage in terms of IOVs. The IOCs of the Respondents is $7.7 \%$ while the IOIs constitutes $92.3 \%$. This means that the total performances of Respondents in terms of IOIs are higher than their performances in terms in IOCs.

Various performances of the Respondents in terms of IOVs, IOAs, IOCs and IOIs are observed in the three electronic Media in Kano State and five electronic Media in Kaduna State, which are two States sampled here for the sake of this Research to represent the Eastern Hausa Dialect Area. In the electronic Media in Kano State the highest percentage of performances in terms of IOVs is reflected against the CTV-Kano with $52.96 \%$. The second is reflected against NTA-Kano with $48.04 \%$. The third is reflected against KSR-Kano with $46.32 \%$. In the electronic Media in Kaduna State the highest percentage performances in terms of IOVs is reflected against DITV-Kaduna with $73.43 \%$ the second is reflected against the KSTV-Kaduna with $52.68 \%$ followed by the NTA-Kaduna with $50.17 \%$ then the FRCN-Kaduna with $48.5 \%$ and then lastly the KSMC-Kaduna with $41.19 \%$. When we consider all the performances of the electronic Media in the two States we can observe that the highest percentage of performances in terms of IOVs is reflected against the DITVKaduna with seconded by the CTV-Kano followed by KSTV-Kano then the NTA-Kaduna then the FRCN-Kaduna then the NTA-Kano then the KSRKano and then lastly the KSMC-Kaduna. 
When we consider the percentages of performances of the electronic Media in Kano State in terms of IOAs we can observe that the highest percentage of performances is reflected against KSR-Kano with $53.67 \%$ seconded by the NTA-Kano with $52.45 \%$ followed by the CTV-Kano with $47.03 \%$. The percentages of performances in the electronic Media in Kaduna State in terms of IOAs reveal that the highest performance is reflected against KSMC-Kaduna with $58.52 \%$ seconded by FRCN-Kaduna with $51.49 \%$ followed by the NTAKaduna with $49.42 \%$ then the KSTV-Kaduna with $47.31 \%$ and then lastly the DITV-Kaduna with $26.89 \%$. The comparison of the percentages of performances in terms of IOAs in the electronic Media in the two the States reveals that the highest percentage of performances in terms of IOAs is reflected against the KSMC-Kaduna seconded by the KSR-Kano followed by NTA-Kano then the FRCN-Kaduna then the NTA-Kaduna then the KSTV-Kaduna then the CTVKano then lastly the DITV-Kaduna.

In terms of $I O C s$ in the electronic Media in Kano State the highest percentage of performances is reflected against the NTA-Kano with $7.7 \%$ seconded by the CTV-Kano with $5.65 \%$ and then lastly the KSR-Kano with $4.71 \%$. In the electronic Media in Kaduna State, the percentages of performances in terms of IOCs show that the highest performance is reflected against the DITV-Kaduna with $12.06 \%$ seconded by the NTA-Kaduna with $4.31 \%$ followed by the KSMC-Kaduna with $3.56 \%$ then the KSTV-Kaduna with $2.62 \%$ and then lastly the FRCN-Kaduna with $1.72 \%$. The comparison of the percentages of performances in terms of $10 \mathrm{Cs}$ in the electronic Media in the two States reveals that the highest percentage of performances is reflected against the DITV-Kaduna seconded by the NTA-Kaduna followed by the CTV-Kaduna then the KSR-Kano then the NTA-Kaduna then the KSMC-Kaduna then the KSTV-Kaduna and then lastly the FRCN-Kaduna.

The percentages of performances in terms of $\mathrm{IOIs}$ in the electronic Media in Kano State show that the highest percentage of performances is reflected against the KSR-Kano with $95.29 \%$ seconded by the CTV-Kano with $94.35 \%$ followed by the NTA-Kano with $92.3 \%$. The percentages of performances of the electronic media in Kaduna State in terms of IOIs show that the highest performance is reflected by the FRCN-Kaduna with $98.28 \%$ seconded by the KSTV-Kaduna with $97.36 \%$ followed by the KSMC-Kaduna with $96.44 \%$ then the NTA-Kaduna with $95.69 \%$ and then lastly the DITV-Kaduna with $87.94 \%$. The comparison of the percentages of performances of the electronic Media in the two States shows that the highest performance in terms of IOIs is reflected against the FRCN-Kano seconded by KSTV-Kaduna followed by KSMCKaduna then the NTA-Kaduna then the KSR-Kano then the CTV-Kano then the NTA-Kano then lastly the DITV-Kaduna.

The Listeners/Viewers sampled out of the in the two States listen/watch electronic Media within and outside the two States. In both States we can classify the electronic Media they listen/watch into three categories: a) the electronic Media within the Eastern Hausa dialect area b) the electronic Media 
within the Western Hausa dialect area and c) the electronic Media within the Non-Hausa speaking area. In addition to the local electronic Media the Hausa Listeners/Viewers prefer to listen to international electronic Media, which broadcast and feature programmes in Hausa. The percentages of the Hausa Listeners/Viewers who prefer to listen to the international Media for Hausa News and feature programmes are higher than the percentages of the Hausa Listeners/ Viewers of the local electronic Media. This may be connected to the relatively higher performances of the international Media in terms of the use of the language i.e. Hausa. It is observed that in both States the percentages of Females who listen/watch Hausa programmes over the electronic Media are smaller than the percentages Males. This may be due to the fact that very few Females are concerned with serious matters in life. Whatever the reason may be the linguistic consequences are enormous. News terms and/or concepts are constantly engineered in order to express new idea and innovations in various domains. Thus the Females may not be aware of these terms and/or concepts, which are in most cases used only over the electronic Media. It is observed that a higher percentage of Hausa Listeners/Viewers in Kaduna claim to misunderstand Hausa terms and/or concepts used over the electronic Media. This may be due to the fact that in Hausa developmental processes the linguistic competence of the Hausa Listeners/Viewers is not taken into cognisance while in Kano, which is more homogeneous in terms of ethnic composition than Kaduna State the Hausa developmental processes take into account the linguistic competence of the Hausa Listeners/Viewers in the State. We can further observe that the percentage of the Hausa Listeners/Viewers in Kaduna who learn Hausa terms and concepts is higher that of Kano State.

It is observed that both States are ethnically and linguistically heterogeneous. Kaduna State is linguistically and ethnically more heterogeneous than Kano State. This is an interesting situation, which needs careful considerations during Hausa developmental processes. It is also identified that Hausa Listeners/Viewers in both States are from various States of the Federation and have acquired the language i.e. Hausa in various places. We can classify the States where they have acquired the language into three: a) the Eastern Hausa dialect area e.g. Kano, Jigawa, Kaduna States etc. b) the Non-Hausa speaking area e.g. Borno, Adamawa, Plateau States etc. c) the Western Hausa dialect area e.g. Sokoto, Zamfara, Katsina, Kebbi States etc. Hausa acquired in these areas reflects some socio-linguistic features that need consideration in Hausa language development.

\section{Summary}

We have observed various degrees performances in terms of $1 O \mathrm{Vs}, I O A s, I O C s$, and IOIS of Respondents in the electronic Media in the Eastern Hausa dialect area. Comparing the percentages of performances of the Respondent in the all the electronic Media here considered in terms of $I O V_{S}$ we can observe that the 
highest percentage of performances of the Respondents is reflected against the CTV-Kano with $52.96 \%$ then the NTA-Kaduna with $50.17 \%$ then the FRCNKaduna with $48.50 \%$ then the NTA-Kano with $48.04 \%$ then the Kano State Radio with $46.32 \%$ then the KSMC-Kaduna with $41.19 \%$. We can observe various percentages of performances in terms of IOVS that vary from one electronic Media to another. In terms of IOAs the highest percentage of performances is reflected against the KSMC-Kaduna with $58.52 \%$ then the Kano State Radio with $53.67 \%$ then the NTA-Kano with $52.45 \%$ then the FRCN-Kaduna with $51.49 \%$ then the NTA-Kaduna with $49.82 \%$ then the KSTV-Kaduna with $47.31 \%$ then the CTV-Kano with $47.03 \%$ then the DITV-Kaduna with $26.89 \%$. From the percentages of performances in terms of IOAs of the electronic Media, which reflect percentages of performances above fifty per cent we can observe that the there are four electronic Media from the Eastern Hausa dialect area. There are sixteen Media electronic Media that reflect percentages of performances below fifty per cent out which there are four from the Eastern Hausa dialect area In terms of IOCs the highest percentage of performances is reflected against the DITV-Kaduna with $12.06 \%$ followed by the NTA-Kano with $7.70 \%$ then followed by the CTV-Kano with $5.65 \%$ then the Kano State Radio with $4.71 \%$ then the NTA-Kaduna with $4.31 \%$ then the KSMC-Kaduna with $3.56 \%$ then the KSTV-Kaduna with $2.62 \%$. From the percentages of performances in terms of IOCs we can deduce that none of the electronic Media reflect a percentage of performances above fifty per cent. We can further observe that in spite of the low percentages of performances in terms of IOCs, the electronic Media that reflect high percentages of performances in terms of IOAs are ranked low in terms of $1 O C s$ and those which reflect low performances in terms of $I O A s$ are ranked high in terms of IOCs. In terms of IOIs the highest percentage of performances is reflected against the FRCN-Kaduna with $98.28 \%$ then the KSTV-Kaduna with $97.36 \%$ then the KSMC-Kaduna with $96.44 \%$ then the NTA-Kaduna with $95.69 \%$ then the CTV-Kano with $94.35 \%$ then followed by the NTA-Kano with $92.30 \%$ the DITV-Kaduna with $87.94 \%$. From the percentages of performances in terms of $101 \mathrm{~s}$ we can deduce that the electronic Media that reflect low percentages of performances in terms of IOAs are those, which reflect high percentages of performances in terms of IOIs. We can further posit that the electronic Media reflect higher percentages of performances in terms IOAs but lower percentages of performances in terms of IOIs.

The percentages of performances in terms of $1 \mathrm{OVs}, 1 \mathrm{OAs}$, IOCs, and $\mathrm{IOIs}$ of the electronic Media in the areas considered i.e. the Eastern Hausa dialect area, reflect various realities in terms of the use of Hausa in the Nigerian electronic Media. These performances differ not only within the same Media establishment but also across Media establishment. Many socio-linguistic factors contributed to these variations in the performances. Among these sociolinguistic factors we have dialectal and linguistic factors. These factors seri- 
ously affect the communicative competence of the language i.e. Hausa, on which Millions of Hausa Listeners/Viewers depend for "participatory Democracy" in this era of the globalisation trend.

\section{REFERENCES}

Abubakar, A. (1983): Generative Phonology and Dialect Variation: Study of Hausa Dialects. Unpublished Ph.D. Thesis, University of London.

Adamu, M. (1970): The Hausa Factor in West African History. Zaria \& Ibadan: A.B.U. \& O.U. Presses.

Ahmed, U. and Daura, B. (1970): An Introduction to Classical Hausa and the Major Dialects. Zaria: NNPC.

Alkali, W.K. (1995): Modernization of Kanuri Lexis in Selected Domain. Unpublished M.A. Dissertation, Dept. of Languages \& Linguistics, University of Maiduguri.

Antia, B. (1992): Translating in the Electronic Media in Borno State. Sint Amandsberg (Belgium), Federation Internationale des Traducteurs (FIT). In: Translatio, XI/ 3:256-279.

Askira, Maryam, G. (1994): A Linguistic Analysis of the Translation from English into Kanuri and Hausa by the Borno State Electronic Media. Unpublished M.A. Dissertation, Dept. of Languages \& Linguistics, University of Maiduguri.

Baldi, S. (1977): Systematic Hausa Bibliography. Rome: Institute Italo-Africano.

Baldi, S. (1983): Les Emprunts Arabes en Swahili et Haoussa. Unpublished Dissertation Le Cercle. Etudes Africaines. Paris III.

Brann, C.M.B. (1993): The Democratisation of Language Use in Public Domain in Nigeria. In: Journal of Modern African Studies. B/4: 639-656.

McIntyre, J. and Meyer-Bahlburg H. (eds.) (1991): Hausa in the Media: A Lexical Guide. Hamburg: Helmut Buske Verlag.

Mclntyre, J. and Meyer-Bahlburg, H. (eds.) (1998): Arbeitsvokabular Deutsch-Hausa (Arbeitsmaterialien zur Afrikanistik VI. Hamburg: LIT Verlag.

Nida, A. Eugene and Taber, R. Charles (eds.) (1982): The Theory and Practice of Translation. Leiden: E.J. Brill.

Nida, E. (1964): Towards a Science of Translation. Leiden: E.J. Brill.

Nida, E. (1976): Translation as Communication. In: Gerard Nickel (ed.): Proceedings of the Fourth International Congress of Applied Linguistics. Stuttgart: Hochul Verlag.

Nida, E. and Taber, C.E. (eds.) (1982): The Theory and Practice of Translation. Leiden: E.J. Brill.

Odumuh, A.O. (1989): The National Language Question in Nigeria. In: Savanna (Zaria) 10/2 (Dec. 1989) 31-40.

Osaji, D. (1997): Place of Nigeria in the Theory of Language Choice. In: Festschrift C.M.B. Brann.

Peterson, T. (et al.) (1965): The Mass Media and Modern Society. Holt Rinehart \& Winston.

Picht, H. and Draskau, J. (1985): Terminology: an Introduction. England: University of Survey.

Pinchuck, Isadore (1977): Scientific and Technical Translation. London: Andre Deutsch Pitch.

Pitch, (et al.) (1985): Terminology: An Introduction. Guideford: University of Survey.

Sabowale Idowu, A. (1985): The Historical Development of Press. In: F.O. Ugboajah (ed.), Mass Communication.

Salomone, F.A. (1975): Becoming Hausa: Ethnic Identity, Change and its Implication for the Study of Ethnic Pluralism and Stratification. In: Africa, (London), 45/3, 410-42.

Salim Bello, Ahmad (1982): Linguistic Borrowing as External Evidence on Phonology: The Assimilation of English Loanwords in Hausa. Ph.D. Dissertation, University of York. 
Simpson, E. (1985): Translating in Nigerian Mass Media: A sociolinguistic Study. In: F.O. Ugboajah (ed.) Mass Communication Culture and Society in West Africa. Munich: Hans Zell. 133-152.

Simpson, Ekundayo (1980): Translation in Nigerian Mass Media: A Sociolinguistic Study. Quebec, International Centre for the Study of Bilingualism.

Ugboajah, F.O. (1976): Nigerian Mass Communication Trends in the African Context. In: Gazette 22, 156-168.

Vinay, J.P. et Darbelnet, J. (1958): Stylistique Comparee du Francais et de l'Anglais. Paris: Marcel Didier.

Yahaya, I.Y. (1988): Hausa a Rubuce: Tarihin Rubuce - Rubuce Cikin Hausa. Zaria: Gaskiya Corporation. 